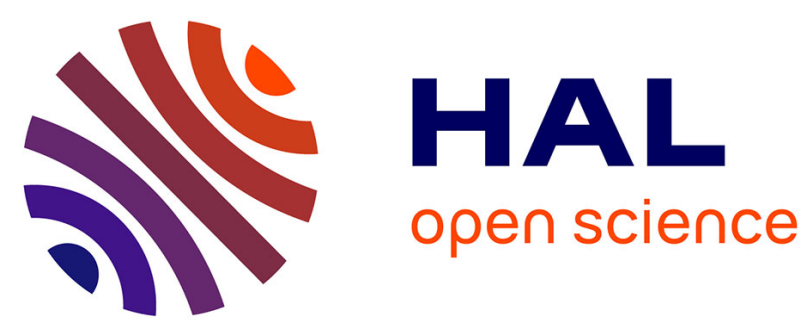

\title{
Do Professional Forecasters Trust in Taylor-Type Rules? - Evidence from the Wall Street Journal Poll
}

Jan Christoph Ruelke, Ralf Fendel, Michael Frenkel

\section{To cite this version:}

Jan Christoph Ruelke, Ralf Fendel, Michael Frenkel. Do Professional Forecasters Trust in Taylor-Type Rules? - Evidence from the Wall Street Journal Poll. Applied Economics, 2011, 45 (07), pp.829-838. 10.1080/00036846.2011.613770 . hal-00743770

\section{HAL Id: hal-00743770 \\ https://hal.science/hal-00743770}

Submitted on 20 Oct 2012

HAL is a multi-disciplinary open access archive for the deposit and dissemination of scientific research documents, whether they are published or not. The documents may come from teaching and research institutions in France or abroad, or from public or private research centers.
L'archive ouverte pluridisciplinaire HAL, est destinée au dépôt et à la diffusion de documents scientifiques de niveau recherche, publiés ou non, émanant des établissements d'enseignement et de recherche français ou étrangers, des laboratoires publics ou privés. 


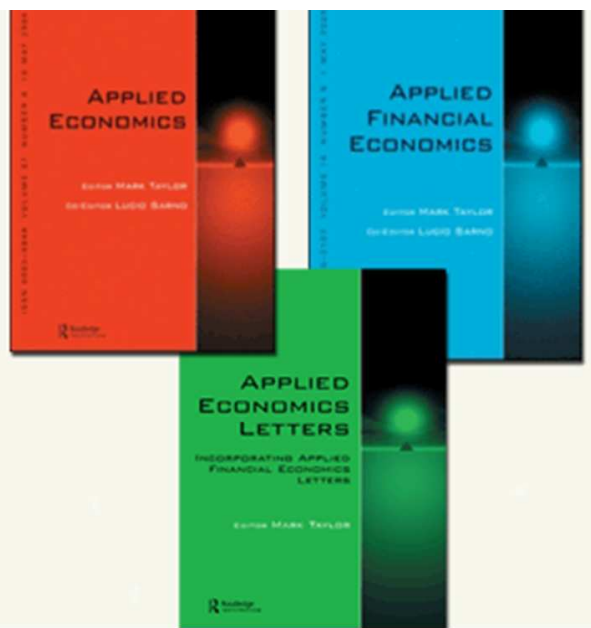

\section{Do Professional Forecasters Trust in Taylor-Type Rules? - Evidence from the Wall Street Journal Poll}

\begin{tabular}{|r|l|}
\hline Journal: & Applied Economics \\
\hline Manuscript ID: & APE-2009-0642.R1 \\
\hline Journal Selection: & Applied Economics \\
\hline Author: & 28-Mar-2011 \\
\hline Complete List of Authors: & $\begin{array}{l}\text { Ruelke, Jan; WHU - School of Manangement, Department of Economics } \\
\text { Fendel, Ralf; WHU Koblenz - Otto Beisheim Graduate School of } \\
\text { Managment, Economics } \\
\text { Frenkel, Michael; WHU Koblenz - Otto Beisheim Graduate School of } \\
\text { Managment, Economics }\end{array}$ \\
\hline JEL Code: & $\begin{array}{l}\text { E51 - Money Supply|Credit|Money Multipliers < E5 - Monetary Policy, } \\
\text { Central Banking, and the Supply of Money and Credit < E - } \\
\text { Macroeconomics and Monetary Economics, D84 - } \\
\text { Expectations|Speculations < D8 - Information and Uncertainty < D - } \\
\text { Microeconomics, C33 - Models with Panel Data < C3 - Econometric } \\
\text { Methods: Multiple/Simultaneous Equation Models < C - Mathematical and } \\
\text { Quantitative Methods }\end{array}$ \\
\hline Keywords: & \begin{tabular}{l} 
Taylor rule, Expectation formation, Monetary policy, Federal Reserve \\
\hline
\end{tabular} \\
\hline \multicolumn{2}{|c}{}
\end{tabular}




\title{
Do Professional Forecasters Trust in Taylor-Type Rules? - Evidence from the Wall Street Journal Poll
}

\author{
March 2011
}

\begin{abstract}
This paper uses the monthly Wall Street Journal poll between 2002 and 2010 to analyze whether professional economic forecasters believe in and, thus, apply Taylor-type rules for their own forecasts. Using their forecasts for the Federal Funds rate, the inflation rate and capacity utilization, we estimate whether these are internally consistent with the message of Taylor(-type) rules. We find that the expectation formation can indeed be described by Taylor-type rules.
\end{abstract}

Keywords: Taylor rule, expectation formation, monetary policy

JEL classification: E52, D84, C33 


\section{Introduction}

In his seminal paper John B. Taylor (1993) explains the development of the Federal Funds rate in terms of a monetary policy reaction function of the Federal Reserve Bank (Fed). The Fed sets the short-term interest rate in accordance with an equilibrium interest rate from which it deviates whenever actual inflation and/or actual output deviate from their respective target values. The so-called Taylor rule has been extended by taking into account the forward-looking behavior of central banks and their intention to smooth the interest rate adjustment. Such Taylor-type rules have gained significant importance in monetary theory and policy. Although the structure of Taylor-type rules is simple, it captures the essence of the behavior of many monetary authorities. Probably due to this feature, the application of Taylor-type rules for describing central bank behavior is not limited to the academic community. Applications can also be found in various publications of the financial industry, when commercial banks and others intend to describe and forecast central bank behavior for their own purposes.

This paper looks more formally at the financial industry and examines whether professional forecasters are really convinced by the validity of such Taylor-type rules and employ them in their forecasts. More precisely, we investigate whether the forecasts of those economists are internally consistent with Taylor-type rules. We use data of the Wall Street Journal (WSJ) poll, as they include, for the U.S. economy, not only interest rate forecasts of individual economists but also forecasts of output and inflation developments.

Since the Taylor-type rules state that output, inflation, and the (policy) interest rate are linked through a certain relationship, it is possible to check 
whether the forecasts are internally consistent (i.e., display relationships known from the estimation of Taylor-type rules) or whether they are inconsistent in the sense that financial market participants talk a lot about Taylor rules when describing the observed behavior of the Fed but do not employ this reasoning in their own forecasts of the Federal Funds rate, the inflation rate and output developments.

This paper also uses a different perspective on interest rate rules compared to their typical use in the academic literature. Rather than employing them to derive central bank reaction functions this paper provides evidence that is relevant for the debate on 'rules versus discretion'. More specifically, we analyze whether the financial market perceives the Fed to be rule-based which, in the forecasts of financial market participants, should lead to a stable relationship between the Federal Funds rate forecasts and the forecasted relevant economic variables. To this extent, the paper is structured as follows: The subsequent section 2 sets out the concept of Taylor-type rules and briefly presents the core results that have emerged from the empirical literature as a yardstick for the subsequent analysis. Section 3 describes the data employed. Section 4 presents the results and section 5 concludes.

\section{The Morphology of Taylor-type Rules}

The central banks of industrial countries typically conduct monetary policy by using market-oriented instruments in order to influence the short-term interest rate. Since the seminal paper of Taylor (1993), it has virtually become a convention to describe the interest rate setting behavior of central banks in terms of monetary policy reaction functions. In its plain form, the so-called Taylor rule states that the central bank reacts to deviations of the inflation rate and output from their respective target values. Clarida et al. (1998) propose a forward-looking variant 
of the Taylor rule which takes into account the pre-emptive nature of monetary policy as well as interest rate smoothing behavior of central banks. This particular type of reaction function has become very popular in empirical studies of Taylor rules. Although it is still in the spirit of the Taylor rule, formulations of this type represent a modification of the original Taylor rule and, thus, the literature often refers to them as Taylor-type rules.

A number of studies have demonstrated that the monetary policy of the Fed can be explained by reaction functions of the Taylor-type rules. The most prominent ones are Taylor (1999), Judd and Rudebusch (1998) and Clarida et al. (2000). While Taylor (1999) studies the fit of the original Taylor rule, Judd and Rudebusch (1998) incorporate interest rate smoothing in a modified version. Finally, Clarida et al. (2000) introduce forward-looking elements. ${ }^{1}$

Following Clarida et al. (1998, 2000) the baseline forward-looking policy rule takes the form:

$$
i_{t}^{*}=\bar{i}+\alpha_{1} E_{t}\left(\pi_{t+k}-\pi^{*}\right)+\alpha_{2} E_{t}\left(y_{t+k}-y_{t+k}^{*}\right),
$$

where $i^{*}$ is the desired level of the nominal short-term interest rate, and $\bar{i}$ is its equilibrium level. The second term on the right-hand side is the expected deviation of the $k$-period ahead inflation rate $(\pi)$ from the target rate $\left(\pi^{*}\right)$ which is assumed to be constant over time. The third term is the expected deviation of the $k$-period ahead level of output $(y)$ from its natural level $\left(y^{*}\right)$, i.e., the output gap. The coefficients $\alpha_{1}$ and $\alpha_{2}$ represent the intensity with which the desired interest rate of the central bank reacts to the inflation rate and the output gap.

The assumption of interest rate smoothing behavior leads to

\footnotetext{
${ }^{1}$ See Hamalainen (2004) for a survey of empirical studies related to the US.
} 


$$
i_{t}=(1-\rho) i_{t}^{*}+\rho i_{t-1}+\nu_{t}
$$

where the parameter $\rho$ (with $0<\rho<1$ ) describes the degree of interest rate smoothing and $\nu_{t}$ represents an i.i.d. exogenous random shock to the interest rate. Combining equations (1) and (2) leads to

$$
i_{t}=(1-\rho)\left(\bar{i}+\alpha_{1} E_{t}\left(\pi_{t+k}-\pi^{*}\right)+\alpha_{2} E_{t}\left(y_{t+k}-y_{t+k}^{*}\right)\right)+\rho i_{t-1}+\nu_{t} .
$$

Equation (3) represents the econometric specification which is commonly used to describe central bank behavior. Since it contains expectations on the right-hand side that are not directly observable, it is common to replace them by the observed ex-post levels of the respective variables and rearrange the estimation equation into a form that contains the expectation errors of the central bank in the error term. This form is then estimated based on the General Methods of Moments. Equation (3) is identical with the plain Taylor rule if $\rho$ is assumed to be zero and the horizon of the forward-looking behavior of the central bank, $k$, is also set equal to zero in econometric exercises.

The main message generated by empirical studies focusing on the Fed can be summarized as follows. First, forward-looking specifications seem to fit the Fed's behavior better than contemporaneous versions. Here, the forward-looking feature is most relevant for the inflation gap with the horizon $(k)$ being about one year. Second, the relevance of the Taylor principle for stability, i.e. a reaction coefficient for inflation being greater than unity, is well demonstrated and its presence is a strong feature for the more recent US monetary policy. Third, the reaction coefficient for the output gap is mostly significant but has a significant lower level compared to the inflation gap coefficient. ${ }^{2}$ Fourth, persistence in the Federal Funds rate

\footnotetext{
${ }^{2}$ In particular, for the output gap the literature demonstrated that it is relevant to discriminate between ex post and real-time data (Orphanides, 2001). We take this issue into account and construct the output gap on the basis of both ex-post and real-time data.
} 
is a strong feature in the data. However, it is not finally clear whether this is due to intended interest rate smoothing by the Fed or whether it is due to a strong autocorrelation in the shocks upon which monetary policy reacts. ${ }^{3}$

Our analysis takes the aforementioned four core results of Taylor-type rules as its starting point and interprets them as (historical) information on the systematic behavior of the Fed that is also available for financial markets participants. If the latter believe in the validity of Taylor-type rules and take this kind of analysis seriously, we should expect to observe this in their joint forecasts for the Federal Funds rate and the inflation and output developments. In this case, the forecasts of the three variables cannot be independent from each other. They rather should display the same links and dependencies that the documented reaction functions of the Fed reveal. We therefore estimate variants of equation (3) based on reported forecasts of financial market participants to answer the question that is raised in the title. ${ }^{4}$ Before we present the results in section 4 , we briefly introduce our data set in section 3 .

\section{Survey Studies and Data}

In this paper, we use data of a survey conducted by the WSJ. In this survey, the WSJ regularly asks professional forecasters to submit their projections of several financial variables such as interest rates, unemployment rates and GDP. The data set that results from this survey has several advantages over other surveys and is, thus, less subject to some of the weaknesses often associated with survey data. First, unlike some other surveys, professional economists who participate in the WSJ poll do not only take a stance on the

\footnotetext{
${ }^{3}$ Since this issue is also not of a strong concern in the present paper, we refer to the recent literature (Rudebusch, 2006).

${ }^{4}$ Thus, instead of directly asking financial market participants whether they believe in the Taylor rules, we search for their 'revealed preferences' concerning the usefulness of Taylor rules.
} 
direction of the expected change of a macroeconomic variable. Rather, they also forecast the level of a macroeconomic variable and, thereby the extent of its change. Second, the survey data are readily available to the public so that our results can easily be verified. Third, the individual forecasts are published together with the names and affiliation of the forecasters. Given that this allows everybody to evaluate the performance of the individual participants, the goodness of the forecasts can be expected to have an effect on the reputation of the forecasters. ${ }^{5}$ This is expected to increase the incentives of the survey participants to submit their very best rather than their strategic forecast (Keane and Runkle, 1990). ${ }^{6}$ Compared to that, Ottaviani and Sørensen (2006) argue that in a forecasting contest forecasters differentiate their predictions from those of competitors. The reason is that a forecaster gains from moving away from his best estimate, since, in this case, the number of forecasters that correctly guess the respective value is lower. Such a forecasting contest seems to be likely whenever the survey publishes the name of the forecaster, as this is the case in the WSJ poll. Other surveys, e.g. the Survey of Professional Forecaster and the Livingston survey, do not publish the name of the forecaster but anonymously report the forecasts.

Although the use of survey data in order to proxy expected inflation rates

\footnotetext{
${ }^{5}$ Mitchell and Pearce (2007), for instance, analyze the accuracy of the WSJ forecasts. They find that a majority of the professional forecasters produce unbiased interest rate forecasts, but the forecasts are indistinguishable from a random walk model and the economists are systematically heterogeneously distributed. Using a multivariate approach Eisenbeis et al. (2002) evaluate the performance of professional forecasters in the WSJ poll relative to the other participants. Their results suggest that the dispersion in the forecasts may serve as an indicator of how much uncertainty there may be about where the economy is going. Greer (2003) concentrates on the one-year forecast of the 30-year U.S. Treasury bond. He examines whether economists are able to predict the direction of change correctly and finds that this is indeed the case.

${ }^{6}$ In contrast to the view of Keane and Runkle (1990), Laster et al. (1999) develop a model in which forecasters are rewarded for forecast accuracy and publicity in case of giving the best forecast at a single point in time. As a consequence, forecasters whose wages depend most on publicity will differ most from the consensus forecast.
} 
as stated in equation (3) is widespread, the academic literature that uses expectations of professional forecasters has focused so far only on whether or not central banks adopt Taylor rules based on public expectations. Reade (2006), for instance, uses monthly data of the University of Michigan survey to estimate Taylor rules for the Fed in a cointegrated VAR model. Using real-time data, he provides support for Taylor rules. Romer and Romer (2002) use the Livingston survey to compare inflation expectations with a simple forward-looking monetary policy rule. Their results suggest that the monetary policy of the Fed varies over time. However, Reade (2006) and Romer and Romer (2002) only use the mean of the poll, whereas the WSJ data set contains individual data of 47 business experts. This allows us to analyze the time as well as the cross section dimension. We, thereby, also take into account the criticism of Giordani and Soederlind (2003) who point out that individual survey data on expectation are preferable to time series models, especially when forecast uncertainty is high.

Greer (1999) uses the semi-annual WSJ poll that has been conducted since 1989 and analyzes whether survey participants applied macroeconomic models in order to forecast macroeconomic variables. His findings cast doubt on the ability of any class of macroeconomic models to predict the development of economic variables. Batchelor and Dua (1990) analyze the forecast accuracy of business experts from the Blue Chip Economic Indicator for the time period of 1981-1986. They focus on the relationship between macroeconomic theories, the applied forecasting methods and the accuracy of the forecasters' predictions for the real growth, the GNP deflator and the three-month Treasury bill rate. Their results suggest that, although Keynesian models are the most popular one, the majority of forecasters assign more weight to independent judgment than to any formal modeling technique. 
Our study investigates whether professional forecaster believe in and, thus, apply Taylor-type interest rate rules. Therefore, we use the monthly data of the WSJ poll for the time period between December 2002 and December 2010. As the monthly WSJ poll does not completely provide January and July forecasts, our analysis covers 87 periods. During this time, 80 forecasters participated at least in one of the 87 surveys. In order to investigate the time series characteristics of the expectation formation process of the participants, we only include professional forecasters participated in all polls. This applies to 47 participants and yields a total of 4,089 forecasts for each variable, i.e. the expected Federal Funds rate, the expected CPI, the expected growth of the GDP, and the expected unemployment rate. Moreover, the professional forecasters are asked to predict the economic variables for two different time horizons, namely for the end of the year and the next mid-year point. ${ }^{7}$ Thus, they provide forecasts for the subsequent (end of) December and the subsequent (end of) June. This leads to a forecast horizon of one to six months and to a forecast horizon of seven to twelve months. Using these alternative time horizons, we distinguish between a short-term and a medium-term Taylor rule.

Table 1 provides an overview of the forecasts as well as the actual data for the sample period December 2002 - December 2010. Table 1 shows that the forecasts provided by the WSJ are - on average - a good predictor for the actual outcome. For instance, while the short-term forecast of the inflation rate (Federal Funds rate) is 2.28 (2.28) the actual mean of the inflation rate (Federal Funds rate) is $2.45(2.31){ }^{8}$ Moreover, the column 'Accuracy' of Table 1 reveals that neither the mean nor the median of the forecasts are

\footnotetext{
${ }^{7}$ Since the forecast horizon of the growth forecasts is on a quarterly basis, we calculate the projected growth rate by weighing the growth rate with the remaining months to the end of the forecast horizon. The appendix provides a detailed description of the calculation.

${ }^{8}$ The same argument applies to the median of the forecast also shown in Table 1.
} 
statistically different from the actual value. ${ }^{9}$ This impression is also conveyed by Figure 1 which shows the actual Federal Funds rate as well as the range of the forecasts concerning the inflation rate (Fed Funds rate) as the (dark) shaded area. The expected Federal Funds rate exhibits a higher volatility compared to the actual series. For instance, between August 2006 and September 2007 (January 2009 and December 2010) the Federal Funds rate was constant at 5.25 percent (0.25 percent). Thus, the Fed did not respond to the inflation rate and output changes during these periods. However, at least some the WSJ economists expected the Federal Funds rate to change. Especially in May 2009 and March 2010, the increase in the expected interest rate seems to be related to an increase in expected inflation. While the data show a substantial degree of heterogeneity concerning the interest rate and inflation rate development, the figure reveals that inflation rate and interest rate expectations respond to each other. For instance, in August 2008 inflation expectations increased to up to 6 percent and simultaneously WSJ forecasters expected the Fed to increase the Federal Funds Rate up to 4 percent while at the same time the actual inflation rate was stable around 2 percent. Apparently, WSJ economists expected that the Fed increased the Federal Funds rate on the basis of the inflation forecasts.

- Insert Figure 1 and Table 1 about here -

Since the WSJ poll reports forecasts for output growth, the most difficult variable to quantify in our framework is the forecast of the output gap $E_{t}\left(\tilde{y}_{t+k}\right)$. We use different forms of the output variable in the Taylor rules. As a first form, we use growth forecasts because these are directly available from the survey. As a second form, we use the industrial production index

\footnotetext{
${ }^{9}$ The fact that the private sector forecasters are known for their relatively good outof-sample forecasting power (Ang et al., 2007) might be a reason why the central bank's behavior can well be described by Taylor rules based on survey data. Gorter et al. (2008) provide evidence that the ECB's monetary policies decisions can be explained by survey data.
} 
$\left(y_{t}\right)$ and combine it with the growth forecast to measure the expected contribution to industrial production $E_{t}\left(\Delta y_{t+k}\right)$ of the period $t+k$. Subsequently, in order to calculate the output trend $y_{t+k}^{*}$, we apply a Hodrick-Prescott filter ${ }^{10}$ to the time period $1995-2010^{11}$ and define the expected output gap as $E_{t}\left(\tilde{y}_{t+k}\right)=y_{t}+E_{t}\left(\Delta y_{t+k}\right)-y_{t+k}^{*}$. Industrial production values in these calculations are from ex-post (revised) data. Then, a positive output gap refers to an upswing of the U.S. economy beyond the trend. A form of the output variable is generated by applying the same methodology as before with the difference that we now use real-time data of industrial production. Monthly real-time observations of industrial production are provided by the Federal Reserve Bank of Philadelphia. ${ }^{12}$ Since we analyze the expectation formation process of a specific point in time, it is reasonable to analyze the information that was available to market participants at the respective time of their forecast, i.e. real-time data. We, thus, employ three different output variables: (i) reported output growth forecasts, (ii) a constructed output gap forecast based on ex-post data, and (iii) a constructed output gap forecast based on real-time data.

Beside the output gap measures, we employ a capacity utilization measure based on the unemployment rate. Since the WSJ poll publishes monthly fixed-event forecasts of the unemployment rate we followed Orphanides and Williams (2007) and use an unemployment argument rather than an output argument in the Taylor rule. We define the expected change in the unemployment rate $E_{t}\left(\tilde{u}_{t+k}\right)$ as the difference between the current value and the expected unemployment rate for the forecast period $t+k$, i.e. $E_{t}\left(\tilde{u}_{t+k}\right)=$

\footnotetext{
${ }^{10}$ More precisely, we use a recursive Hodrick-Prescott Filter with the smoothing parameter set at $\lambda=14,400$. Compared to the standard Filter, the recursive calculation ensures that only information that was available at the time of forecast is taken into account.

${ }^{11}$ We started with this series in 1995 since the OECD calculated the output gap to be zero in 1995.

${ }^{12}$ Croushore and Stark (2001) provide an overview of the real-time database.
} 
$u_{t}-E_{t}\left(u_{t+k}\right) .{ }^{13}$ Using those four alternatives, we are able to employ reasonable robustness checks.

\section{Estimation Results}

In our empirical analysis we start from the econometric specification of the Taylor rule as derived in section 2 and restated below for convenience:

$$
i_{t}=(1-\rho)\left(\bar{i}+\alpha_{1} E_{t}\left(\pi_{t+k}-\pi^{*}\right)+\alpha_{2} E_{t}\left(y_{t+k}-y_{t+k}^{*}\right)\right)+\rho i_{t-1}+\nu_{t}
$$

In order to arrive at a testable relationship, the unobservable terms in equation (3) have to be eliminated. Since our data set allows us to directly observe expectations on the Federal Funds rate, the inflation rate, and output (changes), we only lack information on the equilibrium interest rate and the inflation target. Consistent with Clarida et al. (1998), we treat these two variables as time-invariant and aggregate both of them into the constant. ${ }^{14}$ Thus, we rewrite equation (3) as:

$$
\begin{aligned}
E_{t} i_{t+q}=(1-\rho) \alpha_{0} & +\alpha_{1}(1-\rho) E_{t} \pi_{t+k}+\alpha_{2}(1-\rho) E_{t}\left(\tilde{y}_{t+k}\right) \\
& +\rho i_{t}+\epsilon_{t}
\end{aligned}
$$

where $\alpha_{0}=\bar{i}-\alpha_{1} E_{t} \pi^{*}$.

In equation (4) we use the Federal Funds rate forecast as the left-hand side variable and the actually observed Federal Funds rate as the lagged interest rate as one of the right-hand side variables. In the subsequent regressions, we focus on two different forecast horizons. First, we employ up to sixmonth forecasts of the Federal Funds rate as the left-hand side variable when

\footnotetext{
${ }^{13}$ The choice of using this measure of capacity utilization is superior to the output gap measure discussed above as it circumvents problems associated with the index number theory, the use of industrial production data levels, and exogenous detraining over the whole sample period. Note that by this definition an expected increase (decrease) in the unemployment rate results in a negative (positive) value of $E_{t}\left(\tilde{u}_{t+k}\right)$ in order to produce the same expected sign of the capacity utilization coefficient across all specifications.

${ }^{14}$ However, relaxing the assumption of a time-invariant long-term inflation target $\pi^{*}$ requires an appropriate time-variant measure for $\pi_{t}^{*}$. We leave this to further research.
} 
referring to the short-term forecast. Second, for the medium-term forecast, we employ up to twelve-month forecasts of the Federal Funds rate as the dependent variable. It is not necessary to apply the General Methods of Moments when estimating equation (4), since all expectational variables on the right-hand side are directly observed data. Thus, we employ OLS in our panel estimations. However, the econometric analysis is impaired by the problem of overlapping forecast horizons. This obviously leads to serial correlation in the error terms by construction. In order to overcome the problem of serial correlation in the error terms, we apply a serial correlation model:

$$
\epsilon_{t, i}=\beta_{i} \epsilon_{t-1, i}
$$

where the autoregressive term $\beta_{i}$ measures the degree of persistence in the error term. Additionally, we use Prais-Winsten panel corrected standard errors to account for cross section correlation among the survey participants.

Due to the before-mentioned data availability, we first use output growth forecasts rather than the output gap. For this reason, we slightly depart from specification (4) and estimate the following specification:

$$
\begin{aligned}
E_{t} i_{t+q}=(1-\rho) \alpha_{0} & +\alpha_{1}(1-\rho) E_{t} \pi_{t+k}+\alpha_{2}(1-\rho) E_{t}\left(\Delta y_{t+k}\right) \\
& +\rho i_{t}+\epsilon_{t},
\end{aligned}
$$

where the output gap has been substituted by the growth rate of output. More precisely, it is often argued in the literature that the central bank reacts to a deviation of the actual or expected growth rate of output from a target growth rate (i.e. an output growth gap). Since our sample period is relatively small, we assume a constant target growth rate, which leads to equation (6). Subsequently, we also estimate the Taylor rule based on the expected output gap (equation (4)) which we calculate using the output growth forecast. Therefore, the growth forecast needs to be combined with 
observed data. For this procedure, we use ex-post data on output before we calculate, as an alternative, the expected output gap on the basis of real time data both according to the method laid out before. Finally, as indicated before, we use the expected change in the unemployment rate as an alternative measure of capacity utilization. However, we do not restate the respective econometric specification as it is close to equation (6).

Table 2 shows the estimation results for the Taylor rule on the basis of the four types of capacity utilization measures. The top section of the Table shows the estimates of equation (6) for the short-term, the medium-term, and a forward-looking specification. As mentioned before, this specification uses output growth forecasts as the output variable. The first two regressions are contemporaneous versions, i.e. all variables enter with the same time index. The first equation regresses the up-to-six-month Federal Funds rate forecast on the forecasts of inflation and output growth up to six months (i.e., $q=k \leq 6$ ). The second regression uses forecast horizons of more than six and up to twelve months for all variables (i.e., $6<q=k \leq 12$ ). In the third regression, we regress the up-to-six-month forecast of the Federal Funds rate on the up-to-twelve month forecasts of the output growth and the inflation rate (i.e., $q \leq 6$ and $6<k \leq 12$ ). This implies that monetary policy is expected to require a six-month period to affect real economy variables. Against the background that the time-lag of the monetary policy is about nine to twelve months, this specification seems reasonable. For the Taylor rules based on the alternative measures for capacity utilization, we estimate equation (6) and use the same time structure of variables as described above.

Table 2 shows that the Taylor principle, i.e. $\alpha_{1}>1$, indeed holds regardless of the measurement of the output variable. This implies that forecasters in the WSJ poll expect the Fed to actively fight inflationary pressure. The inflation coefficient $\alpha_{1}$ has a reasonable size and is always the 
highest (lowest) in the forward-looking (medium-term) specification.

Table 2 also reports that the output coefficient $\left(\alpha_{2}\right)$ is positive regardless of the measurement of the output variable. The estimated output growth forecast coefficient of about 1.5 in the short-term version implies that forecasters expect the Fed to increase the Funds rate by about 1.5 percent when the U.S. growth rate increases by one percent. In comparison, the expected output gap coefficient $\alpha_{2}$ based on ex-post and real-time data is smaller. However, it is of reasonable magnitude of about .04 and significantly positive.

The results in Table 2 also indicate that in the short-term and the forward-looking specification, the Federal Funds rate forecast is highly dominated by the actual Federal Funds rate which is indicated by a large smoothing parameter of about 0.96. However, the high value of the smoothing parameter has also been documented in the empirical literature on Taylor rules. Although the smoothing parameter is statistically different from one, it is close to one indicating the high persistency characteristics of interest rates. ${ }^{15}$ The medium-term forecast shows a smaller degree of (expected) smoothing of about 0.88 , which is quite plausible given the longer forecast horizon and, hence, the higher likelihood of a change in the Federal Funds rate. The high degree of the smoothing parameter might also reflect that forecasters employ a model-free judgement, e.g. a random walk model, when forecasting the Federal Funds rate. Estimations using only the actual Federal Funds rate show remarkable explanatory power of the Federal Funds rate forecasts. However, the macroeconomic variables add noticeably

\footnotetext{
${ }^{15}$ This finding matches the well-demonstrated phenomenon that expectations in financial markets are rather static than dynamic (Mitchell and Pearce, 2007). Furthermore, Krueger and Kuttner (1996) found that the Federal Funds future market provide efficient predictions on the future path of the Federal Funds rate. As the future and actual path of the Federal Funds rate are close to each other, static expectations seem reasonable as a means to forecast interest rates.
} 
to explanatory power indicating that the reduced form of the Taylor rule is preferable to a random walk model.

Finally, Table 2 reports the results when replacing in equation (6) the expected output gap $E_{t}\left(\Delta y_{t+k}\right)$ by the expected change in the unemployment rate $E_{t}\left(\tilde{u}_{t+k}\right)=u_{t}-E_{t}\left(u_{t+k}\right)$. The results are similar to the results based on the output growth specification. Again, in the short-term and forwardlooking specification the Taylor principle holds and the coefficient $\alpha_{2}$ of the capacity utilization has the expected positive sign. The coefficient in the short-term specification of about 1.03 indicates that the forecasters expect the Fed to decrease the interest rate by about one percent when they expect the unemployment rate to increase by one percent.

- Insert Table 2 about here -

Since the WSJ forecasts have a fixed-target horizon, the coefficients estimated so far could be influenced by the seasonality arising from a decreasing forecast horizon. In order to account for the inherent seasonality in fixed-target forecasts, we split the sample into categories that have exactly the same forecast horizons and estimate equation (6) for each forecast horizon. The results which are available upon request show that the Taylor principle holds in most cases and the capacity utilization coefficient is properly signed. Interestingly, the smoothing coefficient increases as the forecast horizon decreases which reflects that interest rate forecasts are more influenced by the current interest rate when the forecast horizon is small.

Furthermore, in judging which type of models forecasters might use in order to produce forecasts of the Federal Funds rate, we also consider recursive estimations by estimating equation (6) on the basis of time-varying coefficients. The results which are available upon request show that the coefficient for capacity utilization is always positive indicating that the WSJ 
forecasters believe that the Fed responds to the real economy. By contrast, we found that the response to the expected inflation rate is also positive but the Taylor principle does not hold for the whole sample period. However, this does not imply that the WSJ forecasters expect the Fed to act in a destabilizing manner. Since monetary policy stabilization is also achieved when the response to the real economy is substantial a less pronounced response to the inflation rate can be offset by a strong response to the real economy (Galí, 2008).

To exploit the balanced panel structure and to shed some light on the heterogeneity of the individual participants, we estimated equation (6) for each forecaster individually. We found that, while all forecasters expect the Fed to respond to the expected inflation rate and the expected change in capacity utilization, there is a substantial heterogeneity concerning the degree of the response. While 30 forecasters show an inflation coefficient higher than one, 17 forecasters have an inflation coefficient smaller than one. This reflects that most of the forecasters expect the Taylor principle to hold.

\section{Conclusion}

This paper uses the WSJ poll to analyze whether professional economic forecasters believe in and, thus, apply Taylor-type rules for their forecasts. We test whether the structure of Taylor rules are also present in the forecasts of macroeconomic variables and find that Federal Funds rate forecasts are, indeed, internally consistent with the message of Taylor-type rules regardless of the type of output variable used in the specifications. This finding is most evident in the specifications that take the forward-looking behavior into account and represent the preferred specification in the empirical literature on Taylor rules. 
The results indicate that there is a stable structure in the forecasts of financial markets. This finding can be interpreted as evidence that financial market participants indeed believe that the Fed follows a particular rule, which they, in turn, apply to their forecasts of the monetary policy of the Fed. Nevertheless, more research can be done in this area. For example, we did not check whether the financial markets believe that the underlying rule is symmetric and whether they might take into account additional macroeconomic variables which they believe the Fed is reacting to. Natural candidates for those augmented rules would be asset prices. There are several candidates for these prices. However, we leave this for future research.

We believe that our paper also contributes to the ongoing discourse on "rules versus discretion". The traditional perspective of this debate focused on the normative debate whether monetary policy should be rule-based or not. Proponents of rule-based monetary policy often point to the potential gains in stability of private sector expectations which, in turn, leads to a more stable macroeconomy. The Taylor rule has recently provided such a rule for central banks and research indeed found that such a rule very well describes the behavior of major central banks. However, whether this kind of rulebased behavior finally leads to a more successful monetary policy in terms of a more stabilized economy is crucially determined by the private sector's perception of the rule. If the private sector does not believe in the rule-based behavior, the presence of the latter is not as efficient as it might be if the private sector were instead convinced by the rule. Our paper contributes to this discourse in a sense that it indicates that the private sector seems to accept (and apply in their forecasts) such a Taylor rule which is often used to describe the behavior of the Fed. 


\section{References}

Ang, Andrew, Geert Bekaert, and Min Wei (2007), Do Macro Variables, Asset Markets or Surveys Forecast Inflation Better?, Journal of Monetary Economics 54, pp. 1163 - 1212.

Batchelor, Roy and Pami Dua (1990), Forecaster Ideology, Forecasting Technique, and the Accuracy of Economic Forecasts, International Journal of Forecasting 6, pp. $3-10$.

Clarida, Richard, Jordi Galí, and Mark Gertler (1998), Monetary Policy Rules in Practice: Some International Evidence, European Economic Review 42 (6), pp. $1033-1067$.

Clarida, Richard, Jordi Galí, and Mark Gertler (2000), Monetary Policy and Macroeconomic Stability: Evidence and Some Theory, Quarterly Journal of Economics 115 (1), pp. 147 - 166.

Croushore, Dean and Tom Stark (2001), A Real-Time Data Set for Macroeconomists, Journal of Econometrics 105, pp. 111 - 130.

Eisenbeis, Robert, Daniel Waggoner, and Tao Zha (2002), Evaluating Wall Street Journal Survey Forecasters: A Multivariate Approach, Business Economics 37 (3), pp. $11-21$.

Galí, Jordi (2008), Monetary Policy, Inflation, and the Business Cycle: An Introduction to the New Keynesian Framework, Princeton Press.

Giordani, Paul and Paul Soederlind (2003), Inflation Forecast Uncertainty, European Economic Review 47 (6), pp. 1037 - 1059.

Gorter, Janko, Jan Jacobs, and Jakob de Haan (2008), Taylor Rules for the ECB using Expectations Data, Scandinavian Journal of Economics 110 (3), pp. $473-488$.

Greer, Mark (1999), Assessing the Soothsayers: An Examination of the Track Record of Macroeconomic Forecasting, Journal of Economic Issues 28 (1), pp. $77-94$.

Greer, Mark (2003), Directional Accuracy Tests of Long-Term Interest Rate Forecasts, International Journal of Forecasting 19 (2), pp. 291 - 298.

Hamalainen, Nell (2004), A Survey of Taylor-Type Monetary Policy Rules, Canadian Department of Finance, Working Paper 2004-02. 
Judd, John P. and Glenn D. Rudebusch (1998), Taylor Rules and the Fed: 1970-1997, FRBSF Economic Review 3, pp. 3 - 16.

Keane, Michael P. and David E. Runkle (1990), Testing the Rationality of Price Forecasts: New Evidence from Panel Data, American Economic Review 80, pp. $714-735$.

Krueger, J. and Ken Kuttner (1996), The Fed Funds Future Rates as a Predictor of Federal Reserve Policy, Journal of Future Markets (16), pp. $865-879$.

Laster, David, Paul Bennett, and In Sun Geoum (1999), Rational Bias in Macroeconomic Forecasts, Quarterly Journal of Economics 114 (1), pp. $293-318$.

Mitchell, Karlyn and Douglas K. Pearce (2007), Professional Forecasts of Interest Rates and Exchange Rates: Evidence from the Wall Street Journal's Panel of Economists, Journal of Macroeconomics, 29 (4), pp. $840-854$.

Orphanides, Anthanasios (2001), Monetary Policy Rules based on RealTime Data, American Economic Review 91 (4), pp. $964-985$.

Orphanides, Athanasios and John C. Williams (2007), Robust monetary policy with imperfect knowledge, Journal of Monetary Economics 54 (5), pp. $1406-1435$.

Ottaviani, Marco and Peter Norman Sørensen (2006), The strategy of professional forecasting, Journal of Financial Economics 81 (2), pp. 441 $-466$.

Reade, J. James (2006), The Taylor Rule in a Real-Time Cointegrated VAR Model of the US, Working Paper, Oxford University.

Romer, Christina D. and David H. Romer (2002), A Rehabilitation of Monetary Policy in the 1950s, American Economic Review 92, pp. 121 127 .

Rudebusch, Glenn D. (2006), Monetary policy inertia - fact or fiction?, International Journal of Central Banking 2, pp. 85 - 135.

Taylor, John B. (1993), Discretion versus Policy Rules in Practice, CarnegieRochester Conference Series on Public Policy 39, pp. 195 - 214. 
Taylor, John B. (1999), A Historical Analysis of Monetary Policy Rules, in: Taylor, John B. (ed.), Monetary Policy Rules, University of Chicago Press. 
Table 1: Descriptive Statistics of the Data Used in the Analysis

\begin{tabular}{|c|c|c|c|c|}
\hline Variable & Mean & Accuracy & Median & Accuracy \\
\hline Fed Funds Rate Forecasts & & & & \\
\hline Short-term & 2.28 & 0.82 & 2.27 & 0.83 \\
\hline Medium-term & 2.54 & 0.70 & 2.49 & 0.73 \\
\hline Actual Interest Rate ${ }^{a)}$ & 2.31 & & 2.31 & \\
\hline Inflation Forecasts & & & & \\
\hline Short-term & 2.28 & 0.88 & 2.30 & 0.91 \\
\hline Medium-term & 2.19 & 0.63 & 2.16 & 0.59 \\
\hline Actual CPI Growth ${ }^{b}$ & 2.45 & & 2.45 & \\
\hline Growth Forecast & +2 & & & \\
\hline Short-term & 2.40 & 0.96 & 2.39 & 0.96 \\
\hline Medium-term & 2.64 & 0.81 & 2.64 & 0.81 \\
\hline Actual Growth Rate $\left.{ }^{b}\right)$ & 1.85 & 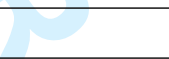 & 1.85 & \\
\hline Unemployment Rate & & & & \\
\hline Forecasts & & & & \\
\hline Short-term & 6.42 & 0.95 & 6.43 & 0.95 \\
\hline Medium-term & 6.39 & 0.97 & 6.41 & 0.96 \\
\hline Actual Unemployment Rate ${ }^{b)}$ & 6.31 & & 6.31 & \\
\hline Groups / Obs. & \multicolumn{2}{|r|}{47} & \multicolumn{2}{|c|}{4,042} \\
\hline
\end{tabular}

Notes: Table 1 reports the expected and the actual mean of the variables for the period December 2002 through December 2010; the data are either provided by a) the Federal Reserve Bank or b) the International Monetary Fund; the last column ('Accuracy') displays the significance level of the t-test on the null hypothesis that the mean (median) of the forecast is equal to the mean of the actual value. 


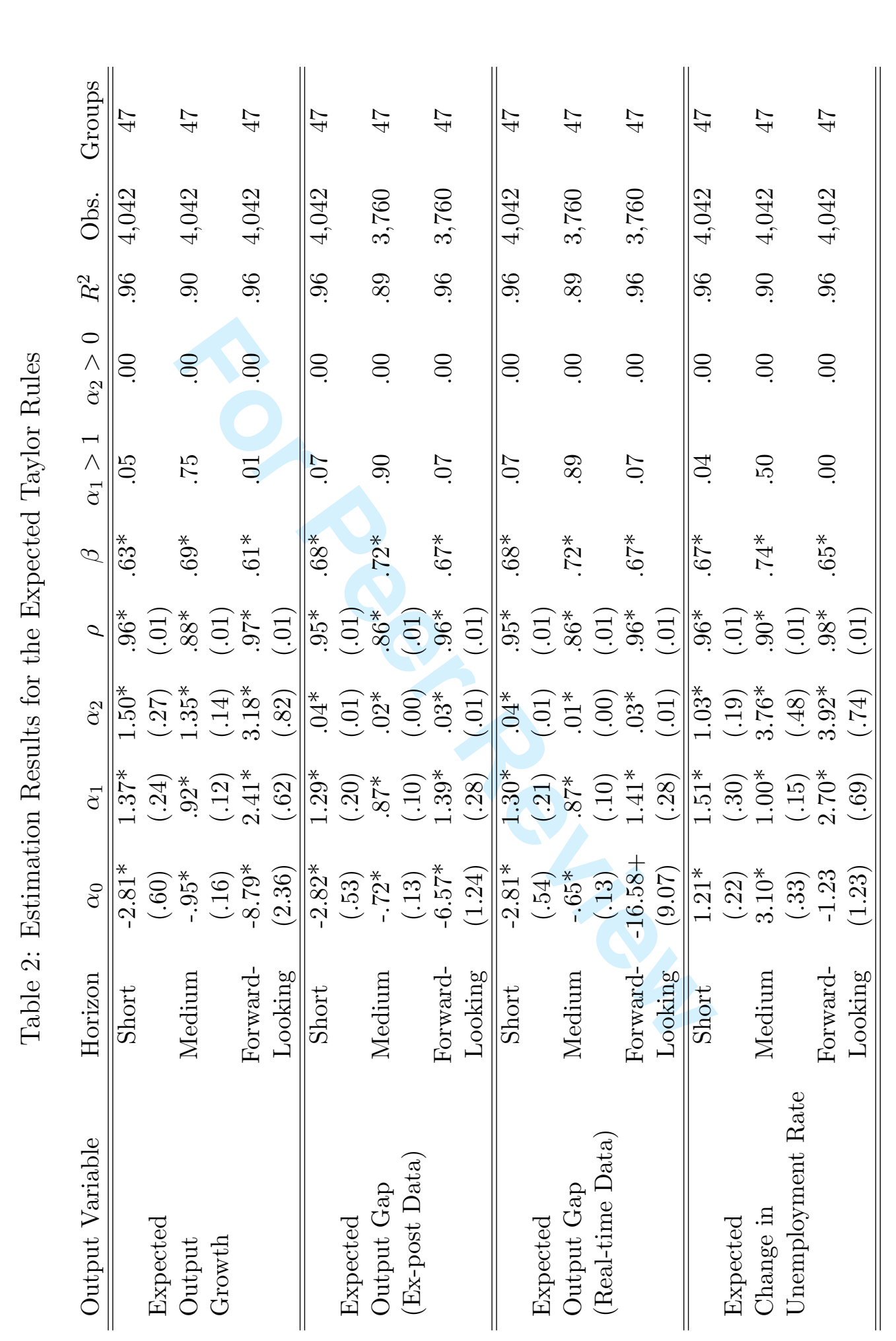

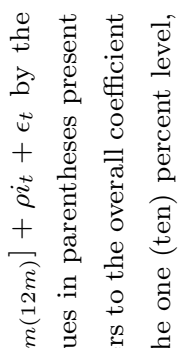


Figure 1: Expected Inflation Rate and Federal Funds Rate

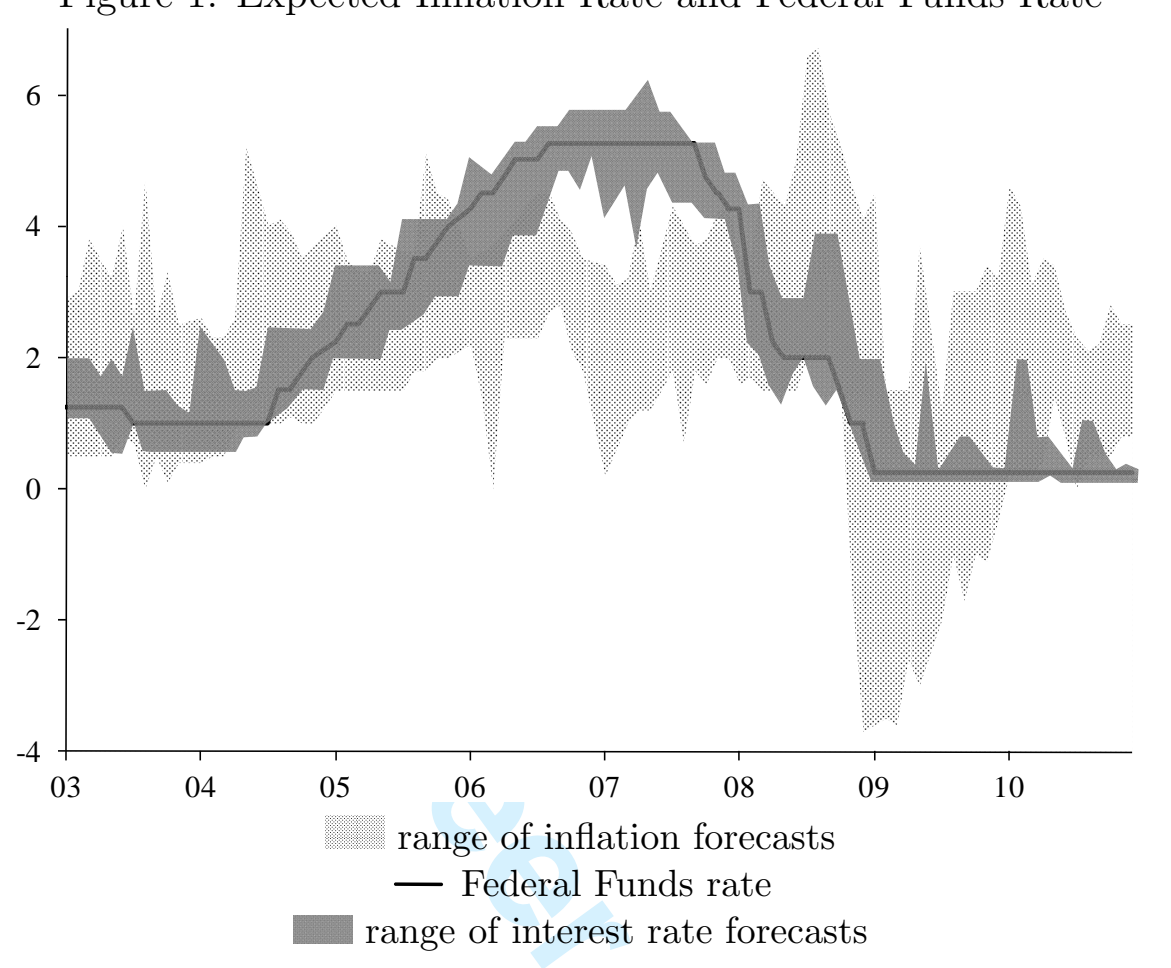

Notes: The line represents the actual Federal Funds rate, while the light-shaded (dark-shaded) area reflects the range of the forecasts concerning the Fed Funds rate (inflation rate). 


\section{Appendix: Calculation of the Weighted Aver- age of Expected GDP}

Since the forecast horizon of the Federal Funds rate and the CPI ends at the middle or the end of the year, whereas the GDP forecasts are provided on a quarterly basis, the GDP forecasts need to be adjusted. To this extent we set the short-term GDP forecasts $\left(E_{t}\left[\Delta y_{t+6 m}\right]\right)$ at time $t(=1,2, . ., 60)$ equal to the forecast of the current quarter $\left(E_{t}[\Delta G D P]_{t}^{1 q}\right)$ whenever the GDP forecast is within the second or fourth quarter. For GDP forecasts collected in the first or third quarter, we calculate the weighted arithmetic average of the forecast by combing the forecast for the current and next quarter $\left(E[\Delta G D P]_{t}^{2 q}\right)$ and weighing the forecasts with the remaining months in the current quarter $(m)$ :

$$
E_{t}\left[\Delta y_{t+6 m}\right]=\frac{m \cdot E_{t}[\Delta G D P]_{t}^{1 q}+3 \cdot E_{t}[\Delta G D P]_{t}^{2 q}}{m+3}
$$

In order to generate a medium-term forecast which is consistent with the forecast horizon of the expected Federal Funds rate and the inflation forecast, we apply the outlined procedure combining the growth forecasts for the next four quarters $\left(E_{t}[\Delta G D P]_{t}^{1 q}, \ldots, E_{t}[\Delta G D P]_{t}^{4 q}\right)$ by weighing the forecast of the current quarter with the remaining months in the current quarter $(m)$. The medium-term GDP forecast $E_{t}\left[\Delta y_{t+12 m}\right]$ is calculated as follows:

$$
E_{t}\left[\Delta y_{t+12 m}\right]=\frac{m \cdot E_{t}[\Delta G D P]_{t}^{1 q}+3 \cdot \sum_{q=2}^{4} E_{t}[\Delta G D P]_{t}^{q}}{m+9}
$$

